\title{
To slay a dragon: Timing of chemotherapy in resectable pleural mesothelioma
}

\author{
Bryan M. Burt, MD, R. Taylor Ripley, MD, and Shawn S. Groth, MD, MS
}

\author{
From the Division of General Thoracic Surgery, The Michael E. DeBakey Department of Surgery, Baylor College \\ of Medicine, Houston, Tex. \\ Disclosures: Authors have nothing to disclose with regard to commercial support. \\ Received for publication Oct 23, 2018; accepted for publication Oct 23, 2018; available ahead of print Dec 6, \\ 2018. \\ Address for reprints: Bryan M. Burt, MD, Division of General Thoracic Surgery, Department of Surgery, Baylor \\ College of Medicine, One Baylor Plaza, BCM 390, Houston, TX 77030 (E-mail: bryan.burt@bcm.edu). \\ J Thorac Cardiovasc Surg 2019;157:767-8 \\ $0022-5223 / \$ 36.00$ \\ Copyright (C) 2018 by The American Association for Thoracic Surgery \\ https://doi.org/10.1016/j.jtcvs.2018.10.110
}

Only the surgeon knows the completeness of resection at the time of pleurectomy/decortication (P/D) or extrapleural pneumonectomy (EPP) for malignant pleural mesothelioma (MPM). MPM is a tumor that develops along pleural surfaces; therefore, resection margins cannot be assessed by conventional methods. A true microscopic complete (R0) resection in MPM is not possible or measurable. Rather, the goal is complete "cytoreduction" through a macroscopic complete (R1) resection, ${ }^{1}$ although this model has recently been challenged by retrospective evidence supporting a survival benefit of less complete (R2) resections. ${ }^{2}$

Because of the inability of surgery alone to effectively treat microscopic disease, resection should be performed only in a multimodality treatment setting, which often includes chemotherapy. ${ }^{3}$ In fact, the survival benefit of surgery alone is inferior compared with surgery as part of a multimodal treatment strategy. ${ }^{4}$ However, the optimal sequence of chemotherapy and surgery is unknown and is currently being evaluated in a randomized phase II trial (NCT02436733).

In their thoughtful analysis of the National Cancer Database, Verma and colleagues ${ }^{5}$ compared induction and adjuvant chemotherapy for patients undergoing resection for node-negative epithelial/biphasic MPM in propensitymatched groups. Overall survival was similar in each group. However, postoperative morbidity and mortality were higher in the induction group. ${ }^{5}$ Although these results seem to favor adjuvant chemotherapy, many patients are unable to receive chemotherapy in the postoperative setting, likely secondary to the extended recovery that patients require to overcome the significant physiologic impact of a P/D or EPP. Unfortunately, these data were not available in this study.

Despite a number of controversies in the multimodal treatment of MPM, such as the use of chemotherapy in the neoadjuvant versus adjuvant setting, the use of EPP versus $\mathrm{P} / \mathrm{D}$, the use of intraoperative adjuvant therapies (heated chemotherapy, Betadine, photodynamic therapy),

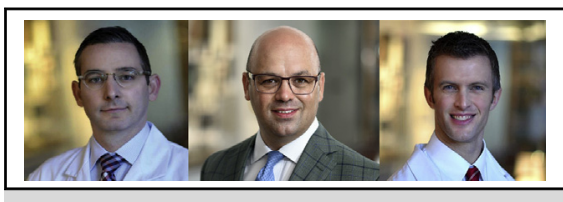

Bryan M. Burt, MD, R. Taylor Ripley, MD, and Shawn S. Groth, MD, MS

Central Message

Innovative treatment approaches to MPM are required to meaningfully affect survival for those with this disease.

See Article page 758.

and the inclusion of radiation therapy (and what modality), the steep descent of modern-day survival curves for MPM is sobering. Although large dataset studies have demonstrated a statistically improved survival for patients undergoing surgery as a component of their treatment regimen, ${ }^{6}$ at times, the survival benefit appears marginal. Offsetting this nihilistic view of the current state of MPM treatment for patients with MPM, there is a growing number of randomized trials in other malignancies demonstrating improved efficacy of immunotherapy in the form of checkpoint blockade, alone and in combination with chemotherapy, compared with standard chemotherapy. Although the published data for checkpoint blockade in MPM are from patients with unresectable disease in phase I and II trials and retrospective analyses, ${ }^{7-9}$ the results are encouraging. Although rates of objective response are approximately $20 \%$, rates of durable clinical response are approximately $50 \%$. It is reasonable to anticipate that incorporating checkpoint blockade into the multimodal approach to MPM including resection may impart a favorable impact on the ominous survival statistics that we have become accustomed to citing.

\section{References}

1. Rice D, Rusch V, Pass H, Asamura H, Nakano T, Edwards J, et al. Recommendations for uniform definitions of surgical techniques for malignant pleural mesothelioma: a consensus report of the international association for the study of lung cancer international staging committee and the international mesothelioma interest group. J Thorac Oncol. 2011;6:1304-12.

2. Batirel HF, Metintas M, Caglar HB, Ak G, Yumuk PF, Ahiskali R, et al. Macroscopic complete resection is not associated with improved survival in patients with malignant pleural mesothelioma. J Thorac Cardiovasc Surg. 2018;155: 2724-33.

3. National Comprehensive Cancer Network 2018. Available at: https://www.ncen org/professionals/physician_gls/pdf/mpm.pdf. Accessed November 29, 2018. 
4. Rusch VW, Giroux D, Kennedy C, Ruffini E, Cangir AK, Rice D, et al. Initial analysis of the international association for the study of lung cancer mesothelioma database. J Thorac Oncol. 2012;7:1631-9.

5. Verma V, Ahern CA, Berlind CG, Lindsay WD, Grover S, Friedberg JS, et al. Treatment of malignant pleural mesothelioma with chemotherapy preceding versus following surgical resection. J Thorac Cardiovasc Surg. 2019;157:758-66.

6. Nelson DB, Rice DC, Niu J, Atay S, Vaporciyan AA, Antonoff M, et al. Long-term survival outcomes of cancer-directed surgery for malignant pleural mesothelioma: propensity score matching analysis. J Clin Oncol. 2017;35: 3354-62.
7. Alley EW, Lopez J, Santoro A, Morosky A, Saraf S, Piperdi B, et al. Clinical safety and activity of pembrolizumab in patients with malignant pleural mesothelioma (KEYNOTE-028): preliminary results from a non-randomised, open-label, phase 1b trial. Lancet Oncol. 2017;18:623-30.

8. Quispel-Janssen J, van der Noort V, de Vries JF, Zimmerman M, Lalezari F, Thunnissen E, et al. Programmed death 1 blockade with nivolumab in patients with recurrent malignant pleural mesothelioma. J Thorac Oncol. 2018;13:1569-76. 9. Metaxas Y, Rivalland G, Klingbiel D, Kao S, Schmid S, Nowak AK, et al. Brief report: pembrolizumab as palliative immunotherapy in malignant pleural mesothelioma. J Thorac Oncol. 2018;13:1784-91. 